
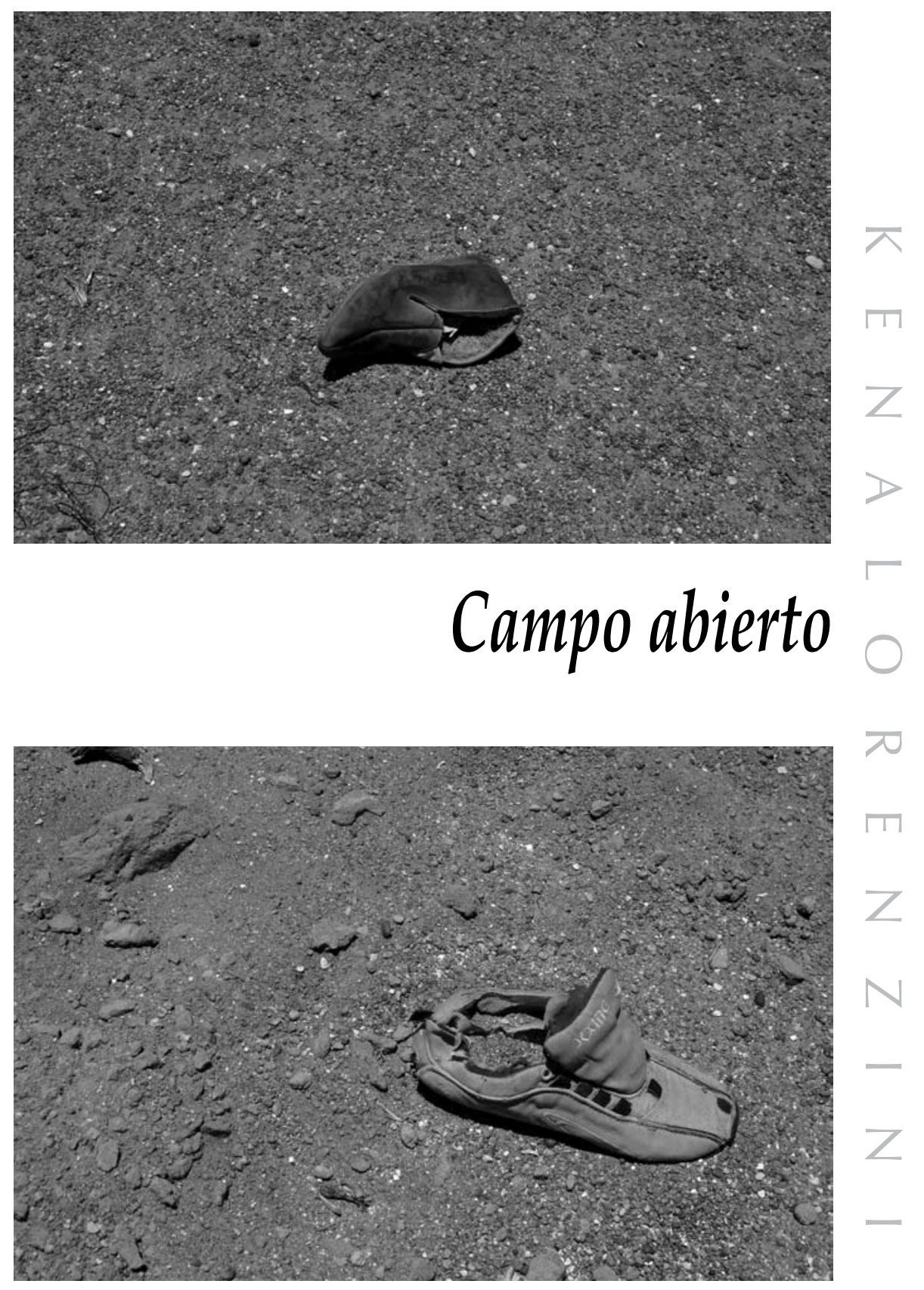

Zapatos Colchane / Diciembre de 2008 


\section{Rosa Araneda: Versera y cronista a pesar de todo. Emergencia de una voz femenina y popular en la segunda mitad del XIX}

\section{Marcela Orellana ${ }^{1}$}

Una de las grandes voces de la Lira Popular corresponde sin duda a Rosa Araneda, autora de una prolífera producción de versos $^{2}$ que abarcan temáticas propias a la cultura de tradición oral como a la citadina y escrita.

Rosa Araneda fue una voz polémica. En constantes desafíos en versos con otros poetas, es acusada de no ser ella quien escribe sus versos, negándosele así un espacio para su voz de mujer y poeta popular en la ciudad de Santiago de la segunda mitad del XIX. En perfectos octosílabos ella se defiende una y otra vez y ataca: "vuélvase mi pluma espada" dice y se caracteriza "como versera y cronista".

Reconociéndola como una poeta de la Lira Popular, intentamos explicarnos su figura desde tres ámbitos de los cuales ella participa: la poesía popular, la ciudad, y lo femenino. Tres ámbitos que en el siglo XIX están inmersos en una dinámica cambiante y de influencias mutuas. En el contexto de la poesía popular, la Lira Popular es el resultado del paso del campo a la ciudad y con ello de la oralidad a la escritura. A su vez, el contexto urbano es el de una ciudad que entra en la modernidad con las transformaciones que ese proceso conlleva. $\mathrm{Y}$ el contexto femenino en fin, donde la mujer decimonónica comienza un camino de conciencia de su identidad femenina y cimienta los primeros pasos del feminismo. Rosa Araneda está en el centro de esos cambios.

Junto a la exposición de estos puntos, acudiremos una y otra vez a su palabra poética a través de la cita de sus versos. ${ }^{3}$ 


\section{1.- La poesía de tradición oral}

La palabra poética tiene en las sociedades de tradición oral la función de memoria de lo que la sociedad quiere conservar y transmitir a las generaciones venideras. De esta manera, las reglas sociales, las creencias y costumbres pasan de generación en generación gracias a distintas formas poéticas: mitos, leyendas, proverbios, adivinanzas y muchos otros.

Esta importante función se resguarda desde la poesía misma. Como la palabra oral no tiene una presencia visual, es solo sonido que se desvanece al pronunciarse sin dejar huella alguna, es muy fácil de olvidar. Así, para poder recordar y mantener esa memoria, el pensamiento debe formularse de manera a no olvidarlo. "Para resolver efectivamente el problema de la retención y recuperación de un pensamiento articulado, este debe hacerse en base a modelos mnemotécnicos, diseñados para una recurrencia oral... El pensamiento está intrínsicamente ligado a los sistemas de memoria". ${ }^{4}$ Es entonces cuando las estructuras poéticas, con sus ritmos, repeticiones y figuras mnemotécnicas juegan un papel fundamental para la memoria de un pueblo.

Otra manera de resguardar la conservación de lo que se quiere traspasar a las generaciones futuras es un complejo sistema de reglas y prohibiciones para decir esa palabra poética, de manera que no cualquiera puede adjudicarse el rol de portavoz de una palabra, así como, en algunas culturas, existen también momentos propicios prohibidos para cada palabra. ${ }^{5}$

Respecto de la poesía de tradición oral chilena, Rodolfo Lenz da a conocer una regla de género para su práctica. Afirma:

“Es un rasgo muy característico de la poesía popular chilena el que se divida rigurosamente en una rama masculina $\mathrm{i}$ una femenina. Cada una de ellas tiene sus argumentos, su métrica, su canto i sus instrumentos particulares i propios. Es común a ambas ramas que el canto se hace casi siempre en voz muy aguda; las mujeres usan de preferencia el falsete, lo que produce una impresión extraña al oído alemán. Las cantoras cultivan casi exclusivamente la lírica liviana, el baile y cantos alegres en estrofas de a cuatro, i menos a menudo, de cinco versos; sus instrumentos son el arpa y la guitarra. Los hombres en cambio, se dedican a los escasos restos del canto épico (romances), la lírica seria, la didáctica i la tensón (controversia poética llamada contrapunto). 
La forma métrica preferida es la décima espinela i su instrumento el sonoro guitarrón" (1919, 43 - 44).

Antonio Acevedo Hernández corrobora esta diferencia al hablar de las fondas del XIX: "en todas estas fondas se bebía y cantaba en guitarra, arpa y guitarrón, es decir, canto de mujer: tonada, cueca y canción; y de hombre: verso grande y contrapunto; pero la importancia del artista estaba en relación con el establecimiento donde actuaba..." $(1935,49)$.

¿Cómo comprender esta división de género dentro del sistema de la poesía de tradición oral chilena? Que significa esta delimitación tan clara entre lo que puede hacer un hombre y lo que puede hacer una mujer?

Ligado a la esfera seria está el hombre, encargado también de la didáctica, es decir que es él quien enseña, quien tiene la función de mantener la identidad de la sociedad, traspasando a las generaciones futuras lo que es verdaderamente importante para la comunidad.

La mujer está fuera de lo serio. A ella le corresponde el lugar de la entretención y de la risa. ${ }^{6}$ Mijail Bajtin ha mostrado la fuerza de rebeldía y de crítica que contiene la risa popular, oponiéndose al mundo oficial. En este caso, a la mujer popular se le adjudica esa mirada cuestionadora, muy lejos de los ideales del recato y mesura de la mujer de clases superiores.

Rosa Araneda, tal como los demás poetas de la Lira Popular, ya no de tradición oral propia al medio rural sino impresa en hojas sueltas y citadina, es heredera de la poesía de tradición oral, tanto en su estructura, la décima espinela, como en sus temas, divididos en las dos grandes ramas de la poesía de tradición oral: lo divino y lo humano. En sus hojas sueltas hay cuecas, tonadas y canciones, lo que sería propio de la mujer, pero también, y constituyen mayoría, versos en décimas que tocan temas de la tradición "seria", así como contrapuntos, lo que también sería propio de los hombres.

Si bien Manuel Dannemann cuestiona la vigencia de la estricta división por género de la práctica poética ya en los últimos decenios del XIX, ${ }^{7}$ esta división de género es el antecedente que estaría en el origen del rechazo de los poetas populares a Rosa 
Araneda, no parece aceptable que la voz de una mujer irrumpa en lo que es propio del hombre. El poeta popular Bernardino Guajardo, respetado entre todos, le dedica unos versos.

Por último caballeros

Si hoy mismo a la plaza van

Hasta mujeres verán

Poetas entre los versos.

$Y$ al que fue de los primeros

Ninguno le considera,

Dígase lo que se quiera,

No cabe duda señores,

Que entre tantos trilladores

Echaron a perder la era. ${ }^{8}$

La poesía, tal como la trilla, sería una actividad de hombres y una mujer echaría a perder tanto a la una como a la otra.

Más allá del escándalo de su presencia, y a través de desafíos poéticos publicados en hojas sueltas, varios poetas le niegan una y otra vez la autoría de sus versos, acusándola de que ella no es quien los compone, sino su conviviente, el poeta Daniel Meneses. Ella contesta por la misma vía, en sus hojas.

Esta es mi sabiduría

La que publico hoy en día

Alegan vean qué cosa

Y dicen que no es la Rosa

Quien hace esta poesía.

Culpan a un pobre tullido

Les diré aquí con gran priesa

Los malos de la cabeza.

...

Es mi verdad mis lectores

I me afirmo en lo que hablo

Que aunque sea el mismo diablo

Yo no les aflojo señores

Vengan aquí a mi presencia 
Poetas que tengan moral

De sentido i memorial

A hacerme competencia

Pues yo, con mi intelijencia

Al mejor hago turbar

Rosa Araneda es lúcida respecto de la dificultad de ser mujer en esta práctica y lograr credibilidad como poeta.

Si fuera de mi deber

Muchas cosas contaría

Pero no se me creería

Porque soy una mujer

Sin embargo logra imponerse "como bella y memorista".

\section{2.- El contexto urbano}

La división de géneros para la práctica de la poesía de tradición oral puede desafiarse en el Santiago de la segunda mitad del XIX.

Su ritmo de cambios y sus aires renovados propician una nueva voz.

Como otras ciudades criollas, Santiago cambia su fisonomía tanto en su aspecto físico como en su composición social. A mediados de siglo se inaugura el alumbrado público con 600 lámparas a gas, se crea el transporte urbano con tranvías de sangre que comunica la estación de ferrocarril con el centro de Santiago, el ferrocarril que une la capital con Valparaíso se inaugura en 1863. Por otra parte, "la clase rica de Santiago alcanzó un gran esplendor del que fueron reflejos las casonas o petits-hotels que los más poderosos se hicieron edificar". ${ }^{9}$ A estas obras se suma un interés por actividades culturales a lo que responde la construcción del Teatro Municipal durante los años 50, escenario de zarzuelas y óperas.

Toda esta actividad trae una emigración de las zonas rurales y en consecuencia crecen los suburbios de la periferia donde se instala el bajo pueblo: Chuchunco, frente a la estación de ferrocarriles, 
Guangualí, la población Ovalle junto al Arenal, el Conventillo o "Potrero de la muerte" en las cercanías del matadero de la ciudad, y en los bordes del cinturón agrícola y viñatero que rodeaba el sur de Santiago. ${ }^{10}$ Los conventillos, repartidos en la ciudad misma, también albergan a los pobres.

En este espacio urbano que crece en construcciones y población, al igual que en las demás ciudades latinoamericanas, "quedaron nítidamente separadas dos lenguas. Una fue la pública y de aparato... la otra fue la popular y cotidiana... el habla cortesana se opuso siempre a la algarabía, la informalidad, la torpeza y la invención incesante del habla popular, cuya libertad identificó con corrupción, ignorancia, barbarismo. Era la lengua del común" (Rama, 1984, 51-52).

Esta ciudad en permanente cambio, que va dejando atrás un aspecto y costumbres coloniales, es un medio propicio para Rosa Araneda que va creándose un espacio donde poder manifestarse como "bella y memorista", como mujer y poeta popular.

Los poetas populares que llegan a Santiago adoptan la escritura, e imprimen sus versos en hojas sueltas, actividad ligada, tanto como la prensa, al desarrollo urbano. Fijan así la lengua del común, imponiendo y dando visibilidad a una lengua hasta entonces sin huella. Por medio de las hojas sueltas, esa palabra adquiere una presencia tangible e irrumpe en las calles de la ciudad, se hace ver.

$\mathrm{Al}$ igual que los demás poetas populares, Rosa Araneda publica sus versos en hojas sueltas y las vende en el mercado. Ella es parte de este sector recientemente incorporado a la letra escrita que le permitirá plantar su palabra popular que no tenía espacio en la ciudad letrada.

Yo por la misma razón

Daré explicación extensa

Y así mi pluma comienza

Trabajando entre los dedos

Mejor hallo la escritura

Para ilustrar el talento

O el antiguo testamento

Opino en sentido pleno 
La escritura libera poco a poco al poeta de tradición oral de la necesidad de componer "para no olvidar", y con ello de regirse por reglas y temas preestablecidos. ${ }^{11}$ De esta manera, la incorporación a la escritura lleva paulatinamente a los poetas populares a introducir, junto a los temas tradicionales de la poesía oral, nuevos tópicos citadinos. La voz de un poeta que recreaba temas seculares se involucra en el hoy en día y sus problemas. La situación económica y social del pueblo, los aconteceres políticos, accidentes y crímenes comienzan a llenar sus hojas. En ello la presencia de Rosa Araneda, al igual que la de los poetas, es ruidosa e insolente para el mundo oficial de la ciudad. ${ }^{12}$

Usted porque está en la buena

I gana doble salario

Tiene al pobre operario

Como con una cadena

Días tendrán que llegar

Desde hoy en adelante

Que el pueblo la voz levante

Para hacerse respetar

...

Hasta cuando mis hermanos

Se dejarán dominar

Por los ricos en mi pensar

Que se muestran tan tiranos

Se irán poco a poco imponiendo como protagonistas de sus hojas, personajes propios de la ciudad: artesanos, obreros, políticos y las mujeres.

\section{3.- El contexto femenino}

Pero no solo la ciudad y la fuerte convicción de su voz explican la palabra de Rosa Araneda. El siglo XIX también fue un tiempo de cambio para la mentalidad femenina que se plantea desafíos como género, instala de a poco su voz y realiza acciones que la van insertando en la sociedad de una manera nueva, 
autónoma y fuera del hogar, espacio hasta entonces asignado como natural para su desempeño.

En ese sentido, Rosa Araneda, debe entenderse dentro de un movimiento mayor de conciencia femenina propia a su tiempo, que concierne tanto a la mujer de la oligarquía como a la popular. La mujer de la oligarquía santiaguina organiza en los últimos decenios del siglo los llamados salones del diecinueve, que continuando la tradición de la tertulia colonial, son reuniones en donde se conversa sobre temas de alta cultura como música, literatura, artes y políticas. Es un momento en que "un sector reducido de mujeres interviene y construye una serie de prácticas culturales, que funcionan como estrategias que les permitirán insertarse paulatinamente en el espacio público y, también, período en que se empieza a configurar el espacio literario como tal". ${ }^{13}$ Estas mujeres, señala Dollen el mismo artículo: "son sujetos que están construyendo discursos y prácticas que van más allá de estar dirigidas a coadyuvar en la construcción del espacio público masculino."

La mujer popular, por su parte, debe insertarse en el mundo del trabajo por una cuestión de sobrevivencia. "Durante el siglo XIX se experimentan procesos de cambios que redefinen el papel de la mujer popular dentro de la familia y de la sociedad en general. Se autosustentan gracias a oficios como: la costura, el lavado ajeno, las cocinerías, al comercio ambulante, la prostitución. Las que no viven en los conventillos se emplean en el servicio doméstico puertas adentro y también un pequeño segmento hacia fines del XIX se proletarizó en establecimientos industriales."14

De esta manera, tanto la mujer de la oligarquía como la mujer del pueblo, viven procesos que cuestionan el rol que habían tenido hasta el momento y salen del hogar participando del ámbito de lo público.

Rosa Araneda es parte de ese movimiento social y muy lúcida respecto de su tiempo. Registra en sus hojas el tema de la mujer y su función en la sociedad. Desde sus versos aplaude al grupo organizado de mujeres católicas opositoras a Balmaceda.

Al impulso de mi mano

Yo diré a todas horas

Vivan las opositoras, 
Que por no morir a pausa

Defendieron nuestra causa

Como unas leales señoras

Se lamenta también de la suerte de las más pobres entre las que se percibe una acción colectiva de protesta, con el resultado de la detención por la policía.

Al fin, mujeres también

Pagaron la harina a nueve,

Que es lo que más conmueve

Como en estos versos ven

I hay muchas en el retén

Están para aquella acción

Así, ella destaca a las mujeres organizadas, independientemente de su origen social. El pueblo o la oligarquía no es, en estos casos, lo que las caracteriza, sino el hacerse visibles fuera del hogar manifestando su sentir como grupo de mujeres.

Y así como se empieza a configurar un espacio literario para la mujer de la oligarquía, Rosa Araneda, desde su poesía manuscrita a pluma que puede ser espada cuando tiene que combatir a los poetas que la niegan "vuélvase mi pluma espada / para pagarle bien fuerte" o liviana y temblorosa para relatar una noticia "tiembla la pluma en mi mano / i palpita el corazón", serena en fin desde su posición de poeta popular.

Yo con mi pluma serena

Mas tarde daré la lista

Como bella y memorista

Voi diciendo a la lijera

Instala su voz en esta segunda mitad del XIX.

\section{Conclusión}

El intento de invisibilizar una voz femenina por parte de los poetas populares de la Lira Popular puede ser explicado por las estrictas reglas para la práctica de la poesía de tradición oral 
chilena, antecedente de la poesía popular urbana que fue la Lira Popular en la segunda mitad del XIX y primeras décadas del XX.

Si esto explica la actitud de los poetas populares, dos nuevas realidades de ese momento convergen para permitir la expresión de esa voz popular y femenina.

Estas son, por una parte, la ciudad de Santiago que se transforma física y socialmente, y por otra la emergencia de la mujer como grupo con un pensamiento y una acción femenina que comienza tímidamente a generar espacios para una palabra de mujer. Rosa Araneda es parte de ese movimiento social y es el paso de la oralidad rural a la escritura citadina la que le posibilita ir más allá de si misma e instalar una voz de mujer y de pueblo. Para concluir, dejamos a Ángel Rama, identificando en esta cita la escritura con la ciudad letrada "Todo intento por rebatir, desafiar o vencer la imposición de la escritura pasa necesariamente por ella... Solo en su campo se tiende la batalla de nuevos sectores que disputan posiciones de poder" $(1983,60)$. Es desde la escritura de sus hojas sueltas que Rosa Araneda puede ser una mujer poeta y dar a conocer su voz heredada de la tradición oral, pero transformada por un contexto cambiante en el que nuevas voces se hacen oír. Y ella lo hace...

\author{
"salgo al frente con mi pluma \\ defendiendo mi derecho."
}

\title{
Notas
}

1 Académica e investigadora de la Facultad de Humanidades de la Universidad de Santiago de Chile.

2 Por versos nos referimos aquí a una composición en décima espinela es decir una cuarteta seguida por cuatro décimas que cumplen con una regla: el último verso de la primera décima corresponde al primero de la cuarteta, el último de la segunda décima al segundo de la cuarteta y así sucesivamente, más una décima de despedida que se agregó en la práctica poética de Chile.

3 Usaremos como fuente de sus versos la publicación de gran parte de ellos en Aunque no soy Literaria. Rosa Araneda en la poesía Popular del siglo XIX. Micaela Navarrete, comp. Santiago: Colección de Documentos de Folklore. Ediciones de la Dirección de Bibliotecas, Archivos y Museos, 1998. 
4 Ong, Walter. Orality and Literacy, New York: Menthuen, 1983, 34. (traducción nuestra)

5 Calame-Griaule, Geneviève. Ethnologie et Langage, La parole chez les Dogon. Paris: Editions Gallimard, 1965.

6 No puede interpretarse esto como que es únicamente la mujer la que tiene esa función, porque la décima espinela, en su rama a lo humano, también da lugar al humor y a la risa.

7 "Si bien la división hecha por Lenz del canto masculino y femenino es aceptable en sentido amplio, ni en ese entonces ni en estos días, la guitarra podría considerarse solo de ejecución de mujeres, y, según, el propio investigador, la décima y el guitarrón serían respectivamente, la estrofa y el instrumento preferidos, no privativos, de los cantores". En: Dannemann, Manuel. Tipos humanos en la poesía folklórica chilena. Santiago: Editorial Universitaria, 1995, 37.

8 Hernández, Roberto. El Roto chileno. Valparaíso: Imprenta San Rafael, 1929, 486.

9 Romero, José Luis. Latinoamérica: La ciudad y las ideas. México: Editorial Siglo XXI, 2005, 244.

10 De Ramón, Armando. Santiago de Chile (1541-1991). Madrid: Editorial MAPFRE, 1992.

11 Ong, Walter. Op.cit, capítulo cuarto: la escritura reestructura la conciencia.

12 Los cambios de la poesía oral tradicional respecto de la poesía popular impresa fueron notorios y llevaron a Rodolfo Lenz a caracterizarla como una poesía que "sin ser propiamente una poesía popular sino más bien una poesía culta, vulgarizada y degenerada" en su artículo sobre la poesía popular impresa. Por su parte A. Acevedo en su libro Los cantores populares de Chile habla de una decadencia "la decadencia vino luego, pues el canto quedó circunscrito a los poetas que publicaban hojas sueltas o folletos..."

13 Doll, Darcie. "Desde los salones a la sala de conferencias: mujeres escritoras en el proceso de constitución del campo literario en Chile." Revista Chilena de Literatura. 71 (2007).

14 Brito, Alejandra. "Del rancho al conventillo. Transformaciones en la identidad popular femenina Santiago de Chile, 1850-1920." En Godoy, Lorena (ed.) Disciplina y desacato: construcción de identidad en Chile. Siglos XIX y XX. Santiago: CEDEM, 1995.

\section{Bibliografía}

Acevedo Hernández, Antonio. Tierra Chilena. Santiago de Chile: Ediciones Ercilla, 1935.

Brito, Alejandra. "Del rancho al conventillo. Transformaciones en la 
identidad popular femenina Santiago de Chile, 1850-1920." En Godoy, Lorena (ed.) Disciplina y desacato: construcción de identidad en Chile. Siglos XIX y XX. Santiago: CEDEM, 1995.

Calame-Griaule, Geneviève. Ethnologie et Langage, La parole chez les Dogon. Paris: Editions Gallimard, 1965.

Dannemann, Manuel. Tipos humanos en la poesía folklórica chilena. Santiago: Editorial Universitaria, 1995

De Ramón, Armando. Santiago de Chile (1541-1991). Madrid: Editorial MAPFRE, 1992.

Doll, Darcie. "Desde los salones a la sala de conferencias: mujeres escritoras en el proceso de constitución del campo literario en Chile." Revista Chilena de Literatura. 71 (2007).

Hernández, Roberto. El Roto chileno. Valparaíso: Imprenta San Rafael, 1929.

Lenz, Rodolfo. Sobre la poesía popular impresa de Santiago de Chile. Santiago: Soc. Imprenta i Litografía Universo, 1919.

Navarrete, Micaela, comp. y estudio. Aunque no soy literaria. Rosa Araneda en la poesía popular del siglo XIX. Santiago: Ediciones de la Dirección de Bibliotecas, Archivos y Museos, 1998, 236.

Ong, Walter. Orality and Literacy. New York: Menthuen, 1983.

Rama, Ángel. La ciudad Letrada. Comisión Uruguaya pro Fundación Internacional Ángel Rama, Uruguay: 1984.

Romero, José Luis. Latinoamérica: La ciudad y las ideas. México: Editorial Siglo XXI, 2005. 